\title{
Obesity as a risk factor of in-hospital outcomes in patients with endometrial cancer treated with laparoscopic surgical mode
}

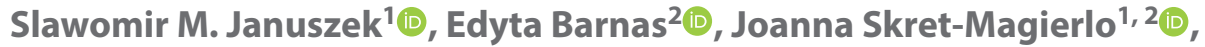

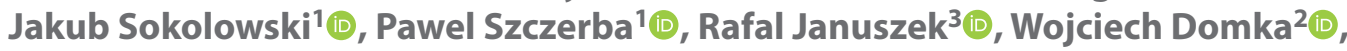 \\ Krzysztof Piotr Malinowski ${ }^{4}{ }^{\oplus}$, Katarzyna Kalandyk-Osinko ${ }^{1,2}$, Marek Kluza ${ }^{1}{ }^{\oplus}$, \\ Aleksandra Bolanowska1 ${ }^{10}$, Tomasz Kluz', 2 (D) \\ ${ }^{1}$ Gynaecology and Obstetrics Clinic, Clinical District Hospital No. 1, Rzeszow, Poland \\ ${ }^{2}$ Medical College of Rzeszow University, Poland \\ ${ }^{3}$ Department of Cardiology and Cardiovascular Interventions University Hospital in Cracow, Poland \\ ${ }^{4} 5^{\text {th }}$ Institute of Public Health, Faculty of Health Sciences, Jagiellonian University Medical College, Cracow, Poland
}

\begin{abstract}
Objectives: Obesity has been suggested to have a negative influence on procedural outcomes of endometrial cancer laparoscopic treatment. Obesity and other possible risk factors of laparoscopic endometrial cancer treatment has not been precisely described in the literature. The aim of the study is to determine the factors that have the greatest influence on the course of laparoscopic surgery for endometrial cancer, with particular emphasis on the influence of obesity.

Material and methods: The study included 75 females who were treated for endometrial cancer by laparoscopic surgery. Preoperative body-mass index (BMI), waist circumference(WC), waist to hip ratio(WHR), and selected anatomical indices were measured. The duration of surgery and hospitalization stay, loss of hemoglobin, and procedural-related complications served as parameters of in-hospital outcomes.

Results: Multiple linear regression analysis indicate the body mass as most sensitive parameter of obesity which influence in-hospital outcomes in patients treated with laparoscopic procedure. Procedural-related complications occurred in the group of patients with significantly greater WC and BMI. Multiple linear regression indicates also histological grading (G1-G3), external conjugate, intertrochanteric distance as significant risk factors. The multiple linear regression analysis confirmed also that implementation of sentinel lymph node procedure is related with decreased hemoglobin loss in patients with cancer of endometrium compare to lymphadenectomy without sentinel node biopsy(Est.: $0.488 ; 95 \% \mathrm{Cl}: 0.083-0.892, \mathrm{p}=0.018$ ).

Conclusions: The most sensitive risk factor of in-hospital outcomes in laparoscopic treatment of endometrial cancer is body mass. The implementation of the sentinel node procedure is associated with reduced surgery time and reduced hemoglobin loss.
\end{abstract}

Key words: obesity; endometrial cancer; risk factors; minimally invasive therapy; sentinel lymph node procedure; total laparoscopic histerectomy; perioperative outcomes

Ginekologia Polska 2020; 91, 10: 573-581

\section{INTRODUCTION}

The most common malignant neoplasm of female reproductive organs is cancer of the endometrium. Incident rates of uterine cancer have increased over successive generations, especially in countries experiencing rapid socioeconomic transition [1]. The risk of developing endometrial cancer by 65 years of age in women ranges from $0.46 \%$ in low/middle developed countries and $0.92 \%$ in highly developed countries [2]. The prevalence of a number of the established risk factors appears to be rising in most parts of the world; obesity, in particular, has doubled in last 30 years globally [3]. While conducting a meta-analysis of 19 review works and prospective trials, it was found that each $5 \mathrm{~kg} / \mathrm{m}^{2}$ increase in BMl caused a significant increase in the risk of developing endometrial-type cancer (RR 1.59, 95\% Cl 1.50-1.68) [4]. In a review conducted among 380 patients with endometrial cancer, it was noted that morbid obesity was connected with higher mortality rate due to 
causes different than endometrial cancer or disease recurrence [5]. Traditionally, obesity was a contraindication to laparoscopic procedures and even constituted an exclusion criterion for laparoscopic surgery. Research published nearly two decades ago revealed that women qualified for laparoscopic management had a substantially lower BMI than those operated on using traditional procedures [6]. Further studies demonstrated that applying laparoscopic procedures in obese patients with endometrial cancer is safe and feasible [7-10]. In a recent study, there is evidence that the oncological efficiency of laparoscopic systematic lymphadenectomy is no less than open-type surgical treatment of patients experiencing intermediate to high-risk endometrial cancer [11]. It was also confirmed that sentinel nodemapping effectively up-staging patients with low or medium risk endometrial cancer and can also be used for high-risk histological types (serous cancer, clear cell carcinoma and carcinosarcoma) [12]. It is possible to distinguish factors modifying the perioperative course of endometrial cancer treatment with the laparoscopic method, taking into account various parameters of obesity, histological type, clinical stage of the cancer, type of lymphadenectomy, age of patients, comorbidities, pelvic anatomical parameters, number of previous abdominal operations. The factors with the greatest impact on the perioperative course of laparoscopic endometrial cancer has not been described in literature on the subject.

The objective of the study was to determine factors having the greatest influence on the course of laparoscopic surgery for endometrial cancer, with particular emphasis on the effect of obesity.

\section{MATERIAL AND METHODS}

This project was an observational prospective-type trial regarding treatment via laparoscopy. Seventy-five patients diagnosed with endometrial cancer qualified for total laparoscopic hysterectomy based on a histopathological examination of uterine scrapings were included in the study. The observation was carried out from January to August 2019.A pre-operative clinical interview was conducted which included questions about age, number of deliveries, education in years, previous abdominal surgery and comorbidities. The following parameters were determined in the preoperative examination: body height and mass, waist and hip circumference $(\mathrm{cm})$ using a tape measure, as well as dimensions of the pelvic bone measured via a pelvis meter. In the study group, body mass index (BMI) and waist-hip ratio (WHR) were calculated for all participants. In accordance with the definition provided by the World Health Organization, obesity regards a BMI value $\geq 30 \mathrm{~kg} / \mathrm{m}^{2}$. Observation of patients covered the period from admission to hospital to discharge from the hospital and outpatient control in the event of postoperative complications. All participants gave informed consent prior to conducting the study. The study was approved by the ethics committee of the Rzeszów University — NO. 4/12/2011.

\section{Eligibility criteria and treatment characteristics}

The study included patients qualified for laparoscopic treatment who expressed informed consent for laparoscopic treatment and expressed informed consent to participate in the observational study. Patients were qualified for laparoscopic treatment in accordance with current Polish guidelines [13].Surgical treatment included: hysterectomy with adnexal removal, sentinel node procedure, pelvic and para-aortic lymphadenectomy. The sentinel node procedure was performed on 34 patients. When the sentinel node procedure was performed, $2 \mathrm{~mL}(1.0 \mathrm{mg} / \mathrm{mL})$ of the dye was injected into the cervical stroma, divided between a superficial injection of 1-3 $\mathrm{mm}$ and a deep injection of $10-20 \mathrm{~mm}$ at 3 and 9 o'clock before entering the manipulator into the uterus. Before hysterectomy, the retroperitoneal spaces were developed and fluorescence imaging was used for sentinel node detection. Identified sentinel nodes were removed and submitted histopathological examination intraoperatively. Patients then underwent hysterectomy and bilateral salpingo-oophorectomy. According to sentinel lymph node procedure (SLNP), all suspicious lymph nodes were excised during the surgical procedure, regardless of mapping. If no lymph nodes were stained (without mapping) on one side of the pelvis, homologous unilateral pelvic lymphadenectomy was performed. Para-aortic lymphadenectomy was performed at the surgeon's discretion. If the sentinel node procedure was not performed, the patient was subjected to hysterectomy as well as bilateral salpingo-oophorectomy. Then patients underwent systematic pelvic and para-aortic lymphadenectomy in some intermediate-risk and all high-risk cases. In intermediate-risk cases(G1/G2 endometrioid cancer and myometrial invasion $(\mathrm{MI})>50 \%$ or $\mathrm{G} 3$ endometrioid cancer and $\mathrm{Ml}<50 \%$ ) lymphadenectomy was considered. In high-risk cases ( $\mathrm{G} 3$ endometrioid cancer and $\mathrm{MI}>50 \%$ ), in all cases of non-endometrioid cancer and all cases of clinical stage II, IIIA, IIIB, a lymphadenectomy was obligatorily performed [13,14].

\section{Study endpoints}

In the perioperative period, the following selected parameters were monitored and recognized as predicators of in-hospital operative treatment outcomes: surgery duration of $(/ \mathrm{min})$, hemoglobin loss recognized as the difference in serum concentration level prior to surgical treatment and on the second day following surgery (in $\mathrm{g} / \mathrm{dL}$ ), the existence of procedure-related complications, and hospitalization duration (/days). 


\section{Statistical analysis}

The continuous variables analysed in the study are expressed as mean \pm standard deviation, while the categorical variables are presented as numbers and percentages. Normality of distribution was evaluated via the Shapiro-Wilk. Continuous variables in selected groups of patients were compared using the Welch test, Kruskal-Wallis test, and the Student's $t$-test when applicable. Categorical variables were compared with the chi square test. Univariate and multivariate linear regression models were applied for analysis of significant predictors regarding selected study endpoints. All potential predictors with clinical values were included into multiple regression modelling. Best models for prediction of hospitalization duration, procedure duration and hemoglobin loss were obtained using backward elimination with Akaike Information Criterion as a target. If two variables were highly correlated (correlation coefficient $>0.7$ ), the strongest predictor was selected. Final results were presented as point estimates with $95 \%$ confidence intervals and p-values. R2 coefficients were calculated. Bootstrap model validation was performed with 1000 iterations. Model assessment was performed by examination of residuals. Statistical analysis was performed in $\mathrm{R}$ version 3.6.2 (R Foundation for Statistical Computing, Vienna, Austria, 2019). The p-value $<0.05$ was considered statistically significant.

\section{RESULTS}

\section{General characteristics}

The study included 75 females treated for endometrial cancer in a laparoscopic way. There were 47 (62.7\%) obese females in the current study (BMI $\geq 30 \mathrm{~kg} / \mathrm{m}^{2}$ ). Patients from the obese group were significantly older when compared to the non-obese patients ( $65.8 \pm 6.2$ vs $59.5 \pm 8.3$ years, $p=0.03$ ). Obese patients originated more often from rural areas when compared to non-obese. However those difference was not significant ( $44.7 \%$ vs $32.1 \%, p=0.28$ ). While non-obese females were more often uniparous when compared to obese $(28.5 \%$ vs $10.6 \%, p=0.04)$. Obese females suffered more often from diabetes $(40.4 \%$ vs $3.5 \%, p=0.004)$, hypothyroidism ( $23.4 \%$ vs $0 \%, \mathrm{p}=0.005)$ and arrhythmias (19.1\% vs $0 \%, p=0.01$ ) when compared to non-obese. The general patients' characteristics in the overall group of patients and according to the obesity status is presented in Table 1. There were no significant statistical differences in the type of procedures used in the groups of patients with and without obesity.

\section{Selected antropometric and anatomical indices}

Obese and non-obese females differ significantly in all the selected parameters of obesity, except for the height, which is presented in Table 2. While among anatomical parameters, all from the selected were longer among obese patients (intertrochanteric, interspinous, intercristal distance and external conjugate) when compared to non-obese, however statistical significance was achieved for intertrochanteric distance $(36.08 \pm 1.54$ vs $35.07 \pm 2.71 \mathrm{~cm}, p=0.01)$ and intercristal distance $(33.08 \pm 2.27$ vs $31.78 \pm 2.78 \mathrm{~cm}$, $\mathrm{p}=0.03$ ) (Tab. 2).

\section{Tumor staging and grading}

Most frequently, patients were diagnosed with stage I cancer (in accordance with the FIGO classification) and then underwent appropriate surgery (Tab. 3). Endometrioid cancer was the most frequent histopathological type (96\%), and most diagnosed at first grade (58.7\%). There were no significant differences between obese and non-obese patients (Tab. 3). While the percentage of females diagnosed at I A stage of FIGO classification was significantly higher among non-obese when compared to obese females ( $42.8 \%$ vs $12.7 \%, p=0.03$ ). This is presented in Table 3 .

\section{Duration of hospitalization}

There was a significant difference in average hospitalization duration, which was notably longer for the obese female patients in comparison to the non-obese $(7.1 \pm 1.4$ vs $5.4 \pm 1.4$ days, $p<0.001$, Fig. $1 C)$. Univariate regression analysis confirmed among predictors related to longer hospitalization time: greater waist circumference $(p<0.001)$, waist-hip ratio $(p<0.001)$, interspinous distance $(p=0.03)$, external conjugate $(p=0.001)$, higher grading $(p=0.03)$, procedural related complications $(p=0.003)$, diabetes $(p=0.01)$, hypothyreosis $(p=0.002)$ and anxiety disorders $(p=0.03)$. The multiple linear regression analysis confirmed among significant predictors of hospitalization time: body mass (Est.: 0.039; 95\% Cl: 0.022-0.056, p < 0.001) and external conjugate (Est.: $0.363 ; 95 \% \mathrm{Cl}: 0.123-0.603$, $p=0.003$ ) (Fig. 2)

\section{Surgery duration}

Surgical procedure duration was noted as significantly longer among the obese females when compared to non-obese females ( $98.1 \pm 16.6$ vs $80.4 \pm 15.2$ min., $p=0.003$ ) (Fig. 1B). The univariate regression analysis revealed among factors related significantly to the longer operation time: waist-hip ratio ( $p<0.001)$, intertrochanteric distance $(p=0.03)$, interspinous distance $(p=0.03)$, intercristal distance $(p=0.02)$, grading $(p=0.005)$, FIGO staging $(p=0.001)$, type of lymhadenectomy ( $p<0.001)$, greater number of concomitant diseases $(p=0.01)$, presence of procedural related complications $(p=0.005)$, hypertension $(p=0.007)$, hypothyroidism $(p=0.008)$, heart failure $(p=0.02)$ and atrial fibrillation ( $p=0.02)$. The significance was confirmed in multiple linear regression analysis for: body mass $t$ (Est.: 0.473 ; 95\% Cl: 0.23-0.716, $\mathrm{p}<0.001)$, intertrochanteric distance 


\begin{tabular}{|c|c|c|c|c|c|}
\hline \multicolumn{2}{|l|}{ Variable } & $\begin{array}{l}\text { Overall group treated by laparoscopy } \\
n=75\end{array}$ & $\begin{array}{l}\text { Obese } \\
n=47\end{array}$ & $\begin{array}{l}\text { Non-obese } \\
n=28\end{array}$ & p-value \\
\hline \multirow{3}{*}{ Place of residency } & Rural region & $30(40.0)$ & $21(44.7)$ & $9(32.1)$ & 0.28 \\
\hline & Urban region & $28(37.3)$ & $16(34.0)$ & $12(42.8)$ & 0.44 \\
\hline & Town $>50,000$ residents & $17(22.7)$ & $10(21.2)$ & $7(25.0)$ & 0.70 \\
\hline \multirow{2}{*}{ Menstrual status } & Before menopause & $9(12.0)$ & $5(10.6)$ & $4(14.2)$ & 0.63 \\
\hline & After menopause & $66(88)$ & $42(89.3)$ & $24(85.7)$ & 0.63 \\
\hline \multirow{3}{*}{ Parity } & Nulliparous & $5(7.0)$ & $4(8.5)$ & $1(3.5)$ & 0.40 \\
\hline & Uniparous & $13(17.0)$ & $5(10.6)$ & $8(28.5)$ & 0.04 \\
\hline & Multiparous & $57(76.0)$ & $38(80.8)$ & $19(67.8)$ & 0.20 \\
\hline \multirow{18}{*}{ Co-morbidities } & Diabetes mellitus & $20(26.7)$ & $19(40.4)$ & $1(3.5)$ & 0.004 \\
\hline & Hypertension & $34(45.3)$ & $25(53.2)$ & $9(32.1)$ & 0.07 \\
\hline & Coronary artery disease & $10(13.3)$ & $8(17.0)$ & $2(7.1)$ & 0.22 \\
\hline & History of venous occlusive disease & $3(5.2)$ & $3(6.4)$ & $0(0)$ & 0.17 \\
\hline & Arrhythmias & $9(12)$ & $9(19.1)$ & $0(0)$ & 0.01 \\
\hline & Prior cerebral stroke & $4(5.3)$ & $3(6.3)$ & $1(3.5)$ & 0.60 \\
\hline & Chronic heart failure & $4(5.3)$ & $3(6.3)$ & $1(3.5)$ & 0.60 \\
\hline & Bronchial asthma & $6(8.0)$ & $5(3.2)$ & $1(3.5)$ & 0.27 \\
\hline & Chronic pulmonary obstructive disease & $8(10.7)$ & $5(3.2)$ & $3(10.7)$ & 0.99 \\
\hline & Hyperthyroidism & $6(8.0)$ & $4(8.5)$ & $2(7.1)$ & 0.83 \\
\hline & Hypothyroidism & $11(14.7)$ & $11(23.4)$ & $0(0)$ & 0.005 \\
\hline & Cholelithiasis & $6(8.4)$ & $5(10.6)$ & $1(3.5)$ & 0.27 \\
\hline & Diathesis urica & $4(5.6)$ & $2(7.1)$ & $2(7.1)$ & 0.59 \\
\hline & Osteoarthritis & $9(12.6)$ & $6(12.7)$ & $3(10.7)$ & 0.79 \\
\hline & Chronic pancreatitis & $8(10.7)$ & $6(12.7)$ & $2(7.1)$ & 0.44 \\
\hline & Chronic gastritis & $6(8.0)$ & $4(8.5)$ & $2(7.1)$ & 0.83 \\
\hline & Peptic ulcer disease & $6(8.0)$ & $5(10.6)$ & $1(3.5)$ & 0.27 \\
\hline & Anxiety disorders & $4(5.3)$ & $4(8.5)$ & $0(0)$ & 0.11 \\
\hline
\end{tabular}

Table 2. Selected antropometric and anatomical indices

\begin{tabular}{|l|l|l|l|l|}
\hline Variable & $\begin{array}{l}\text { Overal group } \\
\mathbf{n}=\mathbf{7 5}\end{array}$ & $\begin{array}{l}\text { Obese } \\
\mathbf{n = 4 7}\end{array}$ & $\begin{array}{l}\text { Non-obese } \\
\mathbf{n = 2 8}\end{array}$ & $\mathbf{p}$-value \\
\hline Weight $[\mathrm{kg}]$ & $84.08 \pm 20.30$ & $94.25 \pm 18.19$ & $67.00 \pm 8.23$ & $<0.001$ \\
\hline Height $[\mathrm{cm}]$ & $161.72 \pm 8.72$ & $161.59 \pm 5.06$ & $161.39 \pm 4.63$ & 0.86 \\
\hline Body-mass index $\left[\mathrm{kg} / \mathrm{m}^{2}\right]$ & $31.13 \pm 7.29$ & $35.99 \pm 6.30$ & $25.65 \pm 2.60$ & $<0.001$ \\
\hline Waist circumference $[\mathrm{cm}]$ & $109.21 \pm 18.78$ & $118.34 \pm 16.63$ & $93.89 \pm 9.69$ & $<0.001$ \\
\hline Hip circumference $[\mathrm{cm}]$ & $114.37 \pm 20.20$ & $122.76 \pm 14.13$ & $100.28 \pm 20.65$ & $<0.001$ \\
\hline Waist-hip ratio & $0.94 \pm 0.05$ & $0.96 \pm 0.04$ & $0.90 \pm 0.05$ & $<0.001$ \\
\hline Intertrochanteric diameter $[\mathrm{cm}]$ & $35.11 \pm 4.37$ & $36.08 \pm 1.54$ & $35.07 \pm 2.71$ & 0.01 \\
\hline Interspinous diameter $[\mathrm{cm}]$ & $27.28 \pm 1.94$ & $27.48 \pm 1.94$ & $26.92 \pm 1.86$ & 0.23 \\
\hline Intercristal diameter $[\mathrm{cm}]$ & $32.60 \pm 2.57$ & $33.08 \pm 2.27$ & $31.78 \pm 2.78$ & 0.03
\end{tabular}

(Est.: 2.225; 95\% Cl: 0.109-4.341, $\mathrm{p}=0.039$ ) and FIGO staging class IIIC2 vs others (Est.: 39.963; 95\% Cl: 11.28-68.645, $\mathrm{p}=0.007)$. This is presented in Figure 3 .

\section{Procedure-related hemoglobin loss}

Values of mean hemoglobin loss were significantly higher during periprocedural time among obese compared to 


\begin{tabular}{|c|c|c|c|c|c|c|}
\hline \multicolumn{3}{|l|}{ Variable } & \multirow{2}{*}{$\begin{array}{l}\text { Overal group } \\
\mathbf{n = 7 5} \\
44(58.7)\end{array}$} & \multirow{2}{*}{$\begin{array}{l}\text { Obese } \\
\mathbf{n}=47 \\
27(57.4)\end{array}$} & \multirow{2}{*}{$\begin{array}{l}\text { Non-obese } \\
\mathbf{n}=\mathbf{2 8} \\
17(60.7)\end{array}$} & \multirow{2}{*}{$\begin{array}{l}\text { p-value } \\
0.78\end{array}$} \\
\hline \multirow{7}{*}{ Histopathological type } & \multirow{3}{*}{ Endometrioid } & G1 & & & & \\
\hline & & $\mathrm{G} 2$ & $25(33.3)$ & $14(29.8)$ & $11(39.2)$ & 0.39 \\
\hline & & G3 & $3(4.0)$ & $3(6.4)$ & $0(0)$ & 0.17 \\
\hline & \multicolumn{2}{|l|}{ Clear-cell } & $1(1,3)$ & $1(2.1)$ & $0(0)$ & 0.43 \\
\hline & \multicolumn{2}{|l|}{ Serous } & $1(1,3)$ & $1(2.1)$ & $0(0)$ & 0.43 \\
\hline & \multicolumn{2}{|c|}{ Adenosquamous } & $1(1.3)$ & $1(2.1)$ & $0(0)$ & 0.43 \\
\hline & \multicolumn{2}{|l|}{ Non-epithelial } & $0(0)$ & $0(0)$ & $0(0)$ & - \\
\hline \multirow{12}{*}{$\begin{array}{l}\text { Staging according to FIGO } \\
\text { classification }\end{array}$} & \multicolumn{2}{|l|}{ Stage I } & & & & \\
\hline & \multicolumn{2}{|l|}{ A } & $18(24)$ & $6(12.7)$ & $12(42.8)$ & 0.03 \\
\hline & \multicolumn{2}{|l|}{ B } & $35(46.7)$ & $24(51.0)$ & $11(39.2)$ & 0.32 \\
\hline & \multicolumn{2}{|l|}{ Stage II } & $13(17.3)$ & $9(19.1)$ & $4(14.2)$ & 0.59 \\
\hline & \multicolumn{2}{|l|}{ Stage III } & & & & \\
\hline & \multicolumn{2}{|l|}{ A } & $3(4.0)$ & $2(4.2)$ & $1(3.5)$ & 0.88 \\
\hline & \multicolumn{2}{|l|}{ B } & $4(5.3)$ & $4(8.5)$ & $0(0)$ & 0.11 \\
\hline & \multicolumn{2}{|l|}{$\mathrm{C} 1$} & $1(2.1)$ & $1(2.1)$ & $0(0)$ & 0.43 \\
\hline & \multicolumn{2}{|l|}{$\mathrm{C} 2$} & $0(0)$ & $0(0)$ & $0(0)$ & - \\
\hline & \multicolumn{2}{|l|}{ Stage IV } & & & & \\
\hline & \multicolumn{2}{|l|}{ A } & $1(2.1)$ & $1(2.1)$ & $0(0)$ & 0.43 \\
\hline & \multicolumn{2}{|l|}{ B } & $0(0)$ & $0(0)$ & $0(0)$ & - \\
\hline
\end{tabular}

A)

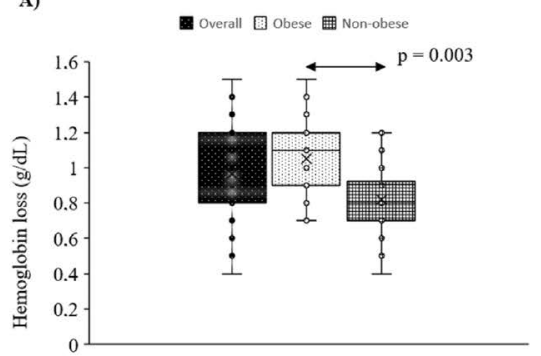

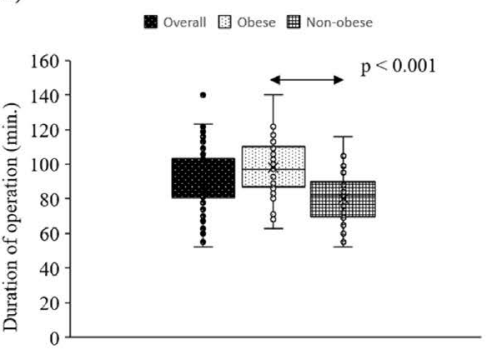

C)

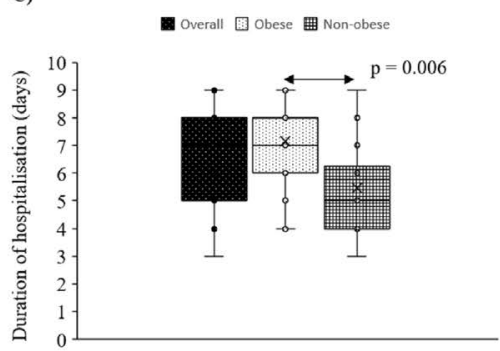

Figure 1. A. Duration of hospitalization according to the obesity status; B. Duration of the operation according to the obesity status; C. Haemoglobin loss after the procedure according to the obesity status

non-obese patients $(1.05 \pm 0.21$ vs $0.82 \pm 0.2 \mathrm{~g} / \mathrm{dL}, \mathrm{p}=0.006)$ (Fig. 1A). The univariate regression analysis demonstrated that among significant predictors related to the greater hemoglobin loss during the procedure there were: tumor staging ( $p=0.002)$, presence of procedural related complications $(p<0.001)$, diabetes $(p=0.05)$, hypothyroidism $(p=0.007)$ and heart failure $(p=0.007)$. The multiple linear regression analysis confirmed among factors significantly related to hemoglobin loss: body mass (Est.: 0.008; $95 \% \mathrm{Cl}$ : $0.006-0.011, p<0.001$ ), sentinel lymph node procedure (Est.: $0.488 ; 95 \% \mathrm{Cl}: 0.083-0.892, \mathrm{p}=0.018$ ), pelvic lymphadenectomy (Est.: $0.535 ; 95 \% \mathrm{Cl}: 0.136-0.935, \mathrm{p}=0.009$ ), and pelvic and para-aortic lymphadenectomy (Est.: 0.62; $95 \%$ Cl: 0.197-1.044, $p=0.004$ ) (Fig. 4).

\section{Procedure-related complications}

Five perioperative complications were noted: postoperative wound infection with impaired healing process in one of the patients, infection of vaginal wound with need of antibacterial systemic therapy in two patients, conversion to open surgery involved with abdominal obesity and pre-peritoneal entry and insufflation, omental damage and bleeding in one patient. All of these complications occurred in obese females. The differences in parameters of obesity between group with and without perioperative complications are statistically significant $(\mathrm{BMI}-37.13$ vs $37.43 p=0.00002$, WC -106.91 vs $141.40 p=0.00003$, WHR -0.93 vs $0.97 p=0.004)$. We did not perform regression analysis due to the fact that were not able to create 


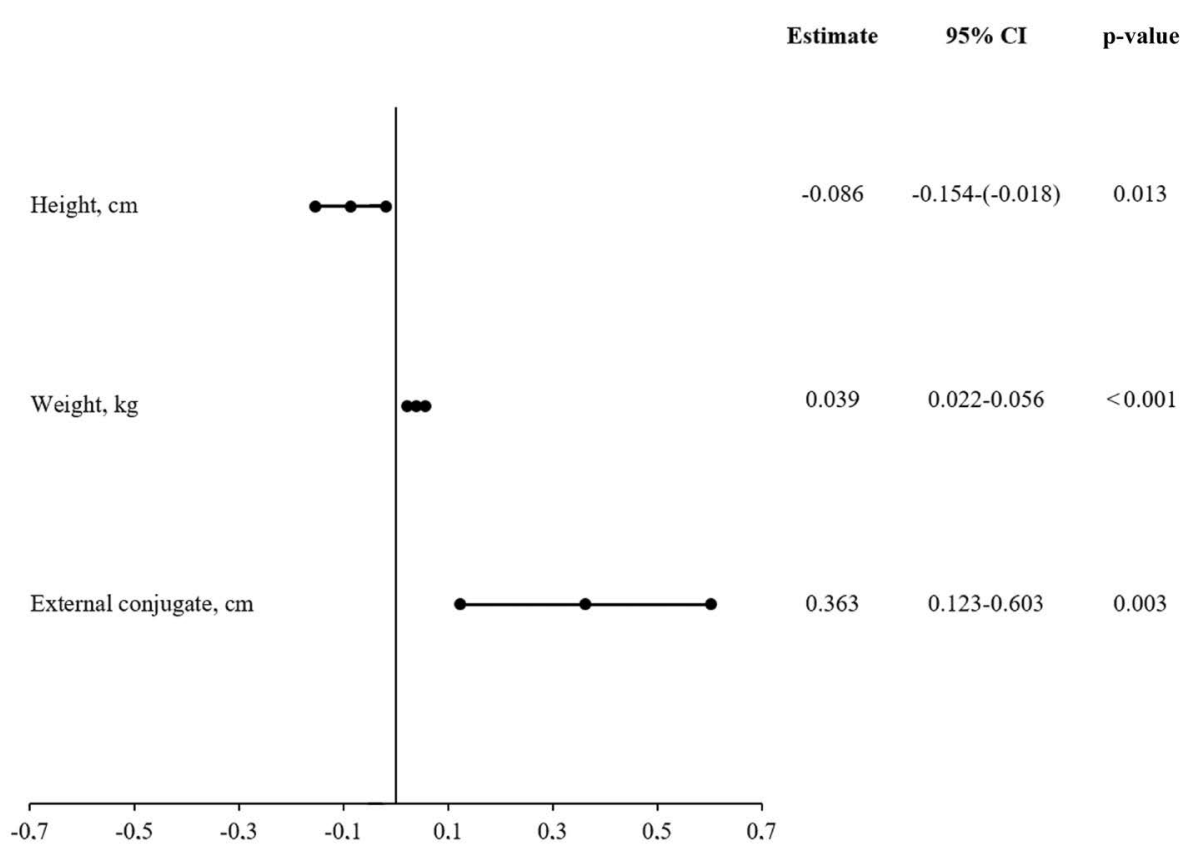

Figure 2. Predictors of the duration of hospitalization - multivariate linear regression analysis

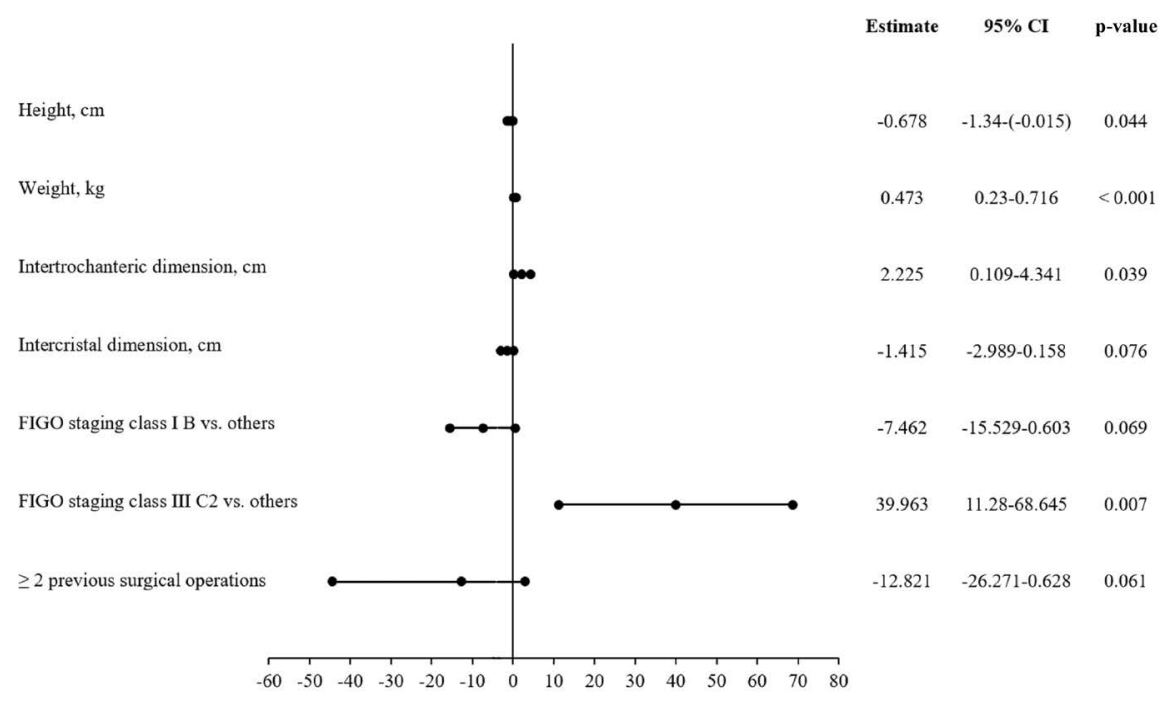

Figure 3. Predictors of the duration of operation - multivariate linear regression analysis

dedicated model, which was caused by lower number of complications in comparison to the number of assessed indices and number of their subclasses.

\section{DISCUSSION}

The general findings of this study are that patients with obesity experienced longer hospitalization as well as surgery duration, higher loss of hemoglobin during the periprocedural period. A further observation worth highlighting is that non-obese subjects were diagnosed with stage IA en- dometrial cancer (in accordance with FIGO classification) more frequently than obese patients. What is more, larger waist-hip ratio, higher grading and FIGO staging as well as greater range of lymphadenectomy were confirmed among the factors related to prolonged surgery time. Predictors of duration of hospitalization were greater waist circumference, waist-hip ratio, external conjugate, higher grading, and procedural related complications. A high correlation to hemoglobin loss were noticed for waist circumstance and BMI ( $r=0.58$ for WC and $r=0.59$ for BMI). However, multiple 


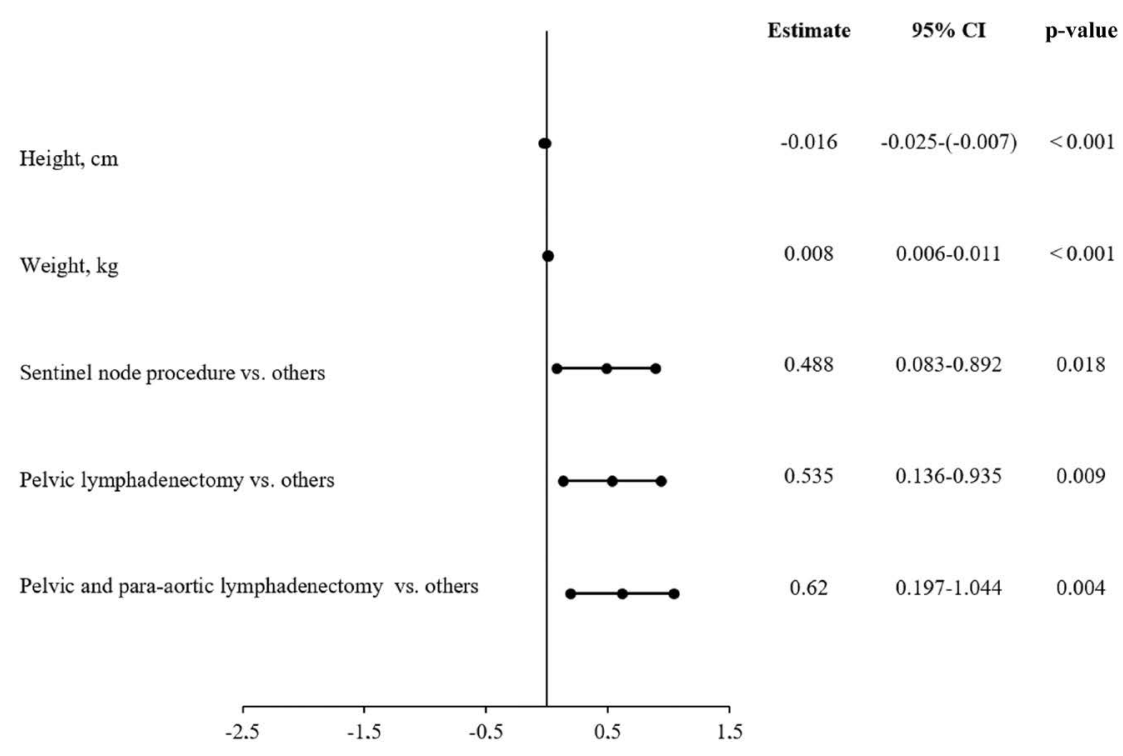

Figure 4. Predictors of the extent of haemoglobin loss according - multivariate linear regression analysis

linear regression analysis indicated weight and range of lymphadenectomy as a factors significantly related to hemoglobin loss. Patients with procedure-related complications were characterized by greater waist circumference and BMI. Multiple linear regression analysis indicated also that greater external conjugate was related to longer hospitalization and greater intertrochanteric distance was related to greater operative time. These observations may result from the fact that larger pelvic dimensions occurred in significantly more obese patients, or from the assumption that greater distances in laparoscopy hinder precision of surgery Yu et al. [10] noted that laparoscopic surgery is safe to use in morbidly obese women with endometrial cancer. Total laparoscopic hysterectomy with lymphadenectomy was also reported to be a safe procedure with benefits of application instead of laparotomy due to: shortened hospital stay, fewer complications, less hemoglobin loss and a better cosmetic result [15-17]. According to Malinowski et al. [18], a total laparoscopic hysterectomy with lymphadenectomy is a better alternative method than laparotomy that is characterized by a significantly smaller percentage of complications, better cosmetic results and a shorter hospital stay when performed by an experienced surgeon. Minimal access surgery appeared to be the preferred approach being associated with a lower pain score, a shorter hospitalization, and an earlier resumption of daily activities when compared with open surgery in randomized controlled trials [19, 20]. The average duration of surgery and hospitalization, as well as hemoglobin loss in the group subjected to endometrial cancer surgical treatment via laparoscopic procedures are similar to results achieved by other centers $[15,21]$. In this trial, greater waist circumference may be connected with longer hospitalization and surgery duration. Among other natural explanations, the more complicated surgical procedure for obese compared to non-obese patients may be given. In the case of gynecological surgery via laparoscopy or using robotic apparatus, the navel may be considered a primary entry-point in the abdominal area for the reason that it is the thinnest part of the abdominal wall [22]. The navel's anatomic location: at aortic bifurcation level in non-obese females - is a significant characteristic point allowing the surgeon to more easily pinpoint critical intra-peritoneal structures during abdominal access via laparoscopy. Along with the increase in rates of obesity, particularly, the amount of women characterized by central adiposity what initiates a shift in this anatomic correlation. The navel is translocated caudally via the panniculus along with the increase in central adiposity, while the relationship between umbilicus and intra-peritoneal structures undergoes change. Abdominal-related obesity also causes an increase in entry depth and furthermore, increases the dangers of pre-peritoneal entry as well insufflation with following conversion to laparotomy. Nonetheless, overall risks related to injury for laparoscopic entry are low when performed by an experienced surgeon [23]. About $50 \%$ of all laparoscopy-related injuries occur at the time of initial abdominal trocar placement $[24,25]$. The chances of laparoscopic injury may be higher among women with abdominal obesity. The left upper quadrant approach was first described by Palmer. It is frequently applied when entry via the umbilicus is challenging or contraindicated, or in cases when periumbilical adhesions, myomatous uteri (organ per- 
foration risk), large ovarian cysts (mass rupture) are suspected, or in the two final trimesters of pregnancy (complication related to excessive bleeding) [22]. In the case of patients with abdominal obesity, the skin to peritoneum distance is increased. This may complicate initial trocar introduction. The advantages of visualizing open laparoscopy (Hasson technique) are restricted due to increased adiposity inherent among obese patients, which can further lead to difficulties in maintaining pneumoperitoneum [26]. Minimal abdominal invasive surgery may be challenging or hazardous in the case of overweight or obese subjects, especially when endometrial cancer is combined with abdominal obesity. The left upper quadrant entry can be a safe, reliable alternative for entry through the umbilical area in high-risk patients [27]. Greater waist circumference as well as BMI were noted in patients who experienced procedure-related complications. Complications following surgery may be early or late. The most commonly noted early complications after laparoscopic surgical gynecology are: conversion to open surgery, pre-peritoneal entry, subcutaneous edema, omental trauma, excessive bleeding, damage to the bladder, ureteral trauma, as well as intestinal perforation. The most frequently observed complications following surgical procedures include infection, difficulty in healing of the wound, thromboembolic and cardiovascular complications, respiratory and renal failure, gastrointestinal obstruction, disorders concerning urination and urogenital as well as intestinal fistulas. The co-morbidity rates regarding obesity and endometrial cancer can be linked with high procedure-related complications. Laparoscopic hysterectomy and bilateral salpingo-oophorectomy have been demonstrated to be the surgical technique of choice for women with endometrial cancer in three large randomized controlled trials $[16,17,28]$. Surgical staging is safe and feasible in a morbidly obese patient when using a minimally invasive approach. In addition, this approach is associated with lower estimated blood loss, length of hospital stay, and fewer perioperative complications. However, longer operating room time (minutes), estimated blood loss $(\mathrm{mL})$ and length of hospital stay were associated with obese patients compared to non-obese [29]. In this study, a correlation was found between obesity (WC and BMI) and perioperative complication occurrence rate. There were statistically significant differences with regard to parameters for the comparative patient group experiencing complications (5 subjects). In the case of abdominal obesity, chronic inflammation or metabolic disturbances can also be considered as part of the reason for the observed complications following surgery, which may include: infection, difficulty in wound healing, circulatory or respiratory problems. In our trial, univariate regression analysis indicated that waist circumstance and waist-hip ratio have the highest predictive value for the analysed parameters for in-hospital outcomes among patients with endometrial cancer. However, multivariant regression indicates that body mass is the factor determining in-hospital outcomes. It is worth noting that the greater range of lymphadenectomy without sentinel lymph node procedure is a factor related to longer duration of operation and greater hemoglobin loss. The recent application of sentinel lymph node mapping has allowed for high feasibility and safety, as well accuracy in the evaluation of nodal metastasis. In a recent study, evidence could be found indicating that laparoscopic systematic lymphadenectomy is not of lower oncological efficient than open surgery when treating patients with intermediate- or high-risk endometrial cancer [31]. In a number of numerous studies, authors have come to the conclusion that sentinel lymph node mapping may be considered a precise alternative for systemic lymphadenectomy on determining the nodal spread in ECs at an early stage, while being cost-effective for treatment of patients low-risk endometrial cancer. In recent studies, it has also been shown that sentinel lymph node mapping allows upstaging in low- or intermediate-risk endometrial cancer patients for whom adjuvant therapy may be omitted. This strategy may be also applied in high-risk histological cancer types (serous carcinoma, clear cell carcinoma, and carcinosarcoma) [32]. Women with endometrial cancer staged with the sentinel lymph node procedure were more likely to undergo adjuvant treatment when compared to women staged with systemic lymphadenectomy. A decrease in surgery duration and a decreased rate of lymphatic edema strongly motivate the sentinel lymph biopsy concept in patients with high-risk endometrial cancer [33].Our study confirmed that implementation of sentinel lymph node procedure is related with reduced hemoglobin loss and operative time in patients with endometrial cancer compare to lymphadenectomy without sentinel node biopsy.

\section{Limitations}

This study may be considered developmental due to it being conducted on a small sample size. Furthermore, in the conducted analysis, attention was paid to evaluating trends and correlations between individual indicators and the results of treatment among a relatively small patient group.

\section{CONCLUSIONS}

Obesity is related to a longer duration of procedure and hospitalization, and greater hemoglobin loss associated with the laparoscopic treatment of endometrial cancer. Our study indicate the body mass as most sensitive parameter of obesity which influence in-hospital outcomes in patients treated with laparoscopic procedures. Abdominal obesity parameters, especially waist circumference significantly affect in-hospital treatment results. Some anatomical indices such 
as intertrochanteric distance and external conjugate are also significant risk factors for laparoscopic treatment of endometrial cancer. There are statistically significant differences in parameters of obesity between two groups with or without procedural complications. Sentinel lymph node procedure is related with decreased operative time and hemoglobin loss.

\section{Conflict of interest}

The authors declare no conflict of interest.

\section{REFERENCES}

1. Lortet-Tieulent J, Ferlay J, Bray F, et al. International Patterns and Trends in Endometrial Cancer Incidence, 1978-2013. J Natl Cancer Inst. 2018; 110(4): 354-361, doi: 10.1093/jnci/djx214, indexed in Pubmed: 29045681.

2. Ferlay J, Shin HR, Bray F, et al. Estimates of worldwide burden of cancer in 2008: GLOBOCAN 2008. Int J Cancer. 2010; 127(12): 2893-2917, doi: 10.1002/ijc.25516, indexed in Pubmed: 21351269.

3. Finucane $M$, Stevens $G$, Cowan $M$, et al. National, regional, and global trends in body-mass index since 1980: systematic analysis of health examination surveys and epidemiological studies with 960 country-years and 9.1 million participants. The Lancet. 2011; 377(9765): 557-567, doi: 10.1016/s0140-6736(10)62037-5.

4. Renehan AG, Tyson M, Egger M, et al. Body-mass index and incidence of cancer: a systematic review and meta-analysis of prospective observational studies. Lancet. 2008; 371(9612): 569-578, doi: 10.1016/S0140-6736(08)60269-X, indexed in Pubmed: 18280327.

5. von Gruenigen VE, Tian C, Frasure H, et al. Treatment effects, disease recurrence, and survival in obese women with early endometrial carcinoma : a Gynecologic Oncology Group study. Cancer. 2006; 107(12): 2786-2791, doi: 10.1002/cncr.22351, indexed in Pubmed: 17096437.

6. van Wijk FH, van der Burg MEL, Burger CW, et al. [Surgical treatment for endometrial adenocarcinoma: first approaches. Review of the literature]. Gynecol Obstet Fertil. 2003; 31(5): 456-464, doi: 10.1016/s12979589(03)00098-5, indexed in Pubmed: 14567126.

7. Obermair A, Manolitsas TP, Leung Y, et al. Total laparoscopic hysterectomy versus total abdominal hysterectomy for obese women with endometrial cancer. Int J Gynecol Cancer. 2005; 15(2): 319-324, doi: 10.1111/j.15251438.2005.15223.x, indexed in Pubmed: 15823119.

8. Holub Z, Bartös P, Jabor A, et al. Laparoscopic surgery in obese women with endometrial cancer. J Am Assoc Gynecol Laparosc. 2000; 7(1): 83-88, doi: 10.1016/s1074-3804(00)80014-6, indexed in Pubmed: 10648744.

9. Kuoppala T, Tomás E, Heinonen PK. Clinical outcome and complications of laparoscopic surgery compared with traditional surgery in women with endometrial cancer. Arch Gynecol Obstet. 2004; 270(1): 25-30, doi: 10.1007/s00404-003-0488-7, indexed in Pubmed: 12728326.

10. Yu CKH, Cutner A, Mould T, et al. Total laparoscopic hysterectomy as a primary surgical treatment for endometrial cancer in morbidly obese women. BJOG. 2005; 112(1): 115-117, doi: 10.1111/j.1471-0528.2004.0 0335.x, indexed in Pubmed: 15663410.

11. Papathemelis T, Oppermann H, Grafl S, et al. Long-term outcome of patients with intermediate- and high-risk endometrial cancer after pelvic and paraaortic lymph node dissection: a comparison of laparoscopic vs open procedure. J Cancer Res Clin Oncol. 2020; 146(4): 961-969, doi: 10.1007/s00432-019-03122-8, indexed in Pubmed: 31901975.

12. National Comprehensive Cancer Network(NCCN)-Clinical practice guidelines: Uterus Neoplasm/ ENDO-C 2 of 6. https://www.nccn.org/professionals/physician_gls/pdf/uterine.pdf (1.03.2020).

13. Sznurkowski J, Knapp P, Bodnar L, et al. Recommendations of the Polish Gynecological Oncology Society for the diagnosis andtreatment of endometrial cancer. Current Gynecologic Oncology. 2017; 15(1):34-44, doi: $10.15557 / \mathrm{cgo} .2017 .0003$

14. Daraï E, Dubernard G, Bats AS, et al. Sentinel node biopsy for the management of early stage endometrial cancer: long-term results of the SENTI-ENDO study. Gynecol Oncol. 2015; 136(1): 54-59, doi: 10.1016/j. ygyno.2014.09.011, indexed in Pubmed: 25450151.

15. Zullo F, Palomba S, Russo T, et al. A prospective randomized comparison between laparoscopic and laparotomic approaches in women with early stage endometrial cancer: a focus on the quality of life. Am J Obstet Gynecol. 2005; 193(4): 1344-1352, doi: 10.1016/j.ajog.2005.02.131, indexed in Pubmed: 16202724

16. Pellegrino A, Villa A, Fruscio R, et al. Feasibility and morbidity of total laparoscopic radical hysterectomy with or without pelvic limphadenectomy in obese women with stage I endometrial cancer. Arch Gynecol Obstet. 2009; 279(5): 655-660, doi: 10.1007/s00404-008-0790-5, indexed in Pubmed: 18795308.

17. Malinowski A, Pogoda K. [Total laparoscopic radical hysterectomy and bilateral pelvic lymphadenectomy of cervical cancer stage IB--case report]. Ginekol Pol. 2012; 83(2): 136-140, indexed in Pubmed: 22568360.

18. Malinowski A, Majchrzak-Baczmańska D, Pogoda K, et al. Evaluation of total laparoscopic hysterectomy with lymphadenectomy in surgical treatment of endometrial cancers. Ginekol Pol. 2013; 84(3): 197-205, doi: $10.17772 / \mathrm{gp} / 1563$, indexed in Pubmed: 23700847.

19. Bijen CB, Vermeulen KM, Mourits MJ, et al. Safety of laparoscopy versus laparotomy in early-stage endometrial cancer: a randomised trial. Lancet Oncol. 2010; 11(8): 763-771, doi: 10.1016/S1470-2045(10)70143-1, indexed in Pubmed: 20638901.

20. Walker JL, Piedmonte MR, Spirtos NM, et al. Laparoscopy compared with laparotomy for comprehensive surgical staging of uterine cancer: Gynecologic Oncology Group Study LAP2. J Clin Oncol. 2009; 27(32): 5331-5336, doi: 10.1200/JCO.2009.22.3248, indexed in Pubmed: 19805679.

21. Scaletta G, Dinoi G, Capozzi V, et al. Comparison of minimally invasive surgery with laparotomic approach in the treatment of high risk endometrial cancer: A systematic review. Eur J Surg Oncol. 2020; 46(5): 782-788, doi: 10.1016/j.ejso.2019.11.519, indexed in Pubmed: 31818527.

22. Pelosi MA, Pelosi MA. Alignment of the umbilical axis: an effective maneuver for laparoscopic entry in the obese patient. Obstet Gynecol. 1998; 92(5): 869-872, doi: 10.1016/s0029-7844(98)00297-x, indexed in Pubmed: 9794685.

23. Hurd WW, Bude RO, DeLancey JO, et al. The relationship of the umbilicus to the aortic bifurcation: implications for laparoscopic technique. Obstet Gynecol. 1992; 80(1): 48-51, indexed in Pubmed: 1534882.

24. Ahmad G, Baker J, Finnerty J, et al. Laparoscopic entry techniques. Cochrane Database Syst Rev. 2019; 1: CD006583, doi: 10.1002/14651858.CD006583.pub5, indexed in Pubmed: 30657163.

25. Vellinga TT, De Alwis S, Suzuki Y, et al. Laparoscopic entry: the modified alwis method and more. Rev Obstet Gynecol. 2009; 2(3): 193-198, indexed in Pubmed: 19826577.

26. Thepsuwan J, Huang KG, Wilamarta $M$, et al. Principles of safe abdominal entry in laparoscopic gynecologic surgery. Gynecology and Minimally Invasive Therapy. 2013; 2(4): 105-109, doi: 10.1016/j.gmit.2013.07.003.

27. Varghese A, Peijnenburg E, Stone RL, et al. Laparoscopic surgical access in morbidly obese women undergoing endometrial cancer surgery: Repurposing the left upper quadrant approach. Eur J Obstet Gynecol Reprod Biol. 2020; 244:56-59, doi: 10.1016/j.ejogrb.2019.11.007, indexed in Pubmed: 31734624.

28. Janda M, Gebski V, Brand A, et al. Quality of life after total laparoscopic hysterectomy versus total abdominal hysterectomy for stage I endometrial cancer (LACE): a randomised trial. Lancet Oncol. 2010; 11: 772-780.

29. Orekoya O, Samson ME, Trivedi T, et al. The Impact of Obesity on Surgical Outcome in Endometrial Cancer Patients: A Systematic Review. J Gynecol Surg. 2016; 32(3): 149-157, doi: 10.1089/gyn.2015.0114, indexed in Pubmed: 27274182.

30. Santoso JT, Barton G, Riedley-Malone S, et al. Obesity and perioperative outcomes in endometrial cancer surgery. Arch Gynecol Obstet. 2012; 285(4): 1139-1144, doi: 10.1007/s00404-011-2116-2, indexed in Pubmed: 22020677. brak odnośnika w tekście

31. Papathemelis T, Oppermann $\mathrm{H}$, Grafl $\mathrm{S}$, et al. Long-term outcome of patients with intermediate- and high-risk endometrial cancer after pelvic and paraaortic lymph node dissection: a comparison of laparoscopic vs open procedure. J Cancer Res Clin Oncol. 2020; 146(4): 961-969, doi: 10.1007/s00432-019-03122-8, indexed in Pubmed: 31901975.

32. National Comprehensive Cancer Network(NCCN)-Clinical practice guidelines: Uterus Neoplasm/ENDO-C 2 of 6. https://www.nccn.org/professionals/physician_gls/pdf/uterine.pdf (25.04.2020).

33. Abdelazim IA, Abu-Faza M, Zhurabekova G, et al. Sentinel Lymph Nodes in Endometrial Cancer Update 2018. Gynecol Minim Invasive Ther. 2019; 8(3): 94-100, doi: 10.4103/GMIT.GMIT_130_18, indexed in Pubmed: 31544018. 